\title{
Physicochemical and radical scavenging activities of honey samples from Malaysia
}

\author{
Norul Liza A-Rahaman, Lee Suan Chua*, Mohamad Roji Sarmidi, Ramlan Aziz \\ Metabolites Profiling Laboratory, Institute of Bioproduct Development, Universiti Teknologi Malaysia, Johor Bahru, Johor, Malaysia; \\ *Corresponding Author: chualeesuan@utm.my
}

Received 2013

\begin{abstract}
The physical properties, total phenols, total flavonoid content and free radical scavenging activities of honey samples from Malaysia were investigated. The physical properties of Tualang, Gelam and Acacia honey samples, in terms of $\mathrm{pH}$, color, moisture, electrical conductivity and total soluble solid were significantly different $(p=$ 0.000 ). Gelam honey was reported to have the highest total phenols (606.17 mg GAE/kg honey) and flavonoid content (183.43 $\mathrm{mg} \mathrm{RE} / \mathrm{kg}$ honey). Tualang honey was reported to have the highest free radical scavenging activity with the $\mathrm{IC}_{50}$, $72.75 \mathrm{~g} / \mathrm{L}$ compared to Gelam $(77.41 \mathrm{~g} / \mathrm{L})$ and Acacia $(90.83 \mathrm{~g} / \mathrm{L})$. There is no significant difference has been revealed among honey samples for radical scavenging activity $(p=0.827)$. Nevertheless, strong correlation was obtained between $\mathrm{pH}$, color, electrical conductivity and total soluble solid with the scavenging activity of all honey samples with the correlative coefficient, $r$ $=0.979,0.902,0.917$ and 0.957 , respectively. The establishment of the statistical correlation could be useful for honey related industry.
\end{abstract}

Keywords: Total Phenolic Content; Total Flavonoid Content; Radical Scavenging Activity

\section{INTRODUCTION}

Honey is a natural food source that widely used as a traditional medicine. To the best of our knowledge, more than 200 substances including complex sugar and small amount of other substances have been found in honey. The common types of honey found in lowland rain forest of Peninsular Malaysia are Tualang and Gelam honey, originates from Tualang (Koompassia excels) and Gelam (Melaleuca cajuputi) trees. Another common source of honey in Malaysia is Acacia honey and this honey is easily available all over the world with different physical and chemical characteristics.
Honey is widely used as antioxidant to reduce the risk of heart disorder, cancer and to increase the immune system [1]. The antioxidant activity of honey is believed mainly contributed by the presence of phenolic acids, flavonoids, catalases, peroxides, carotenoids and nonperoxidal components. According to Gheldof and Engeseth [2] and Turkmen et al. [3], the composition of honey is highly dependent on the botanical and geographical origin, as well as the handling process during harvesting and storage. There are also studies reported that the botanical origin is the critical factor influencing the antioxidant activity of honey $[4,5]$.

There are several methods commonly used for the measurement of antioxidant activity of honey based on different principles and experimental condition. According to Bertoncelj et al. [6], the methods include FRAP assay (ferric reducing antioxidant power), TEAC (Trolox equivalent antioxidant activity), DPPH (1, 1-diphenyl2-picrylhydrazyl) and ORAC (oxygen radical absorbance capacity). DPPH method is likely to be the most reliable technique to determine the antioxidant activity of honey, since DPPH produces stable free radicals for testing [7].

Since honey varies according to their origin, the physical properties of honey samples including $\mathrm{pH}$, color, moisture, electrical conductivity and total soluble solid were studied and correlated statistically with their total phenols, total flavanoids and antioxidant activity. The establishment of the physicochemical correlation enhances the understanding of honey characteristics from tropical country which is beneficial to honey related industry. The findings from this study could be compared to the data reported previously which found the physical properties were highly correlated with the antioxidant activity of honey $[6,8,9]$. Therefore, this study was investigated the physical properties, phenolic and flavonoid contents, as well as the antioxidant activity of honey samples from Malaysia.

\section{MATERIALS AND METHODS}

\subsection{Honey Samples}

All honey samples were collected from the West Coast 
of Peninsular Malaysia, which consist of Tualang, Gelam and Acacia honey. Tualang and Gelam honey was obtained from the Federal Agricultural Marketing Authority (FAMA), Kedah, whereas MB An-Nur Apiary, Johor, supplied the Acacia honey. Honey samples were stored in glass containers at room temperature $\left(25^{\circ} \mathrm{C}-30^{\circ} \mathrm{C}\right)$ in the dark place without any processing or treatment prior to analysis. The analyses were carried out within six months after harvesting.

\subsection{Reagents and Standard}

All reagents are of analytical grade otherwise stated. HPLC-grade of methanol from Merck (Darmstadt, Germany). Hydrochloric acid, sodium hydroxide and aluminium trichloride were purchased from Fisher Scientific (Pittsburg, USA). Deionized water was produced by Barnstead NANOpure Diamond water purification system at $18.2 \mathrm{M} \Omega^{-\mathrm{cm}}$ resistivity (State of Illinois, USA). The standard reagents such as Folin-Ciocalture reagent, 2-2-diphenyl-1-picryhydrazyl and gallic acid were purchased from Sigma-Aldrich (Missouri, USA). Ascobic acid $(98 \%)$ and rutin $(97 \%)$ were obtained from Across Organics (Pittsburg, USA).

\subsection{Physical Analysis}

Determination of $\mathrm{pH}$ : The $\mathrm{pH}$ value of honey was determined based on the method described by Saxena et al. [9] using a pH meter (Mettler Toledo Delta 320) for the measurement. A $10 \% \mathrm{w} / \mathrm{v}$ of honey solution was prepared in aqueous medium.

Determination of color: The color of honey was measured by using Lovibond Honey Photometer based on the AOAC Official Method 985.25 (2000) with minor modification. Honey samples were placed in a $10 \mathrm{~mm}$ pathlength plastic cuvette. The color values was determined in triplicate and expressed in millimeter Pfund scale.

Determination of moisture content: The moisture content was measured based on the AOAC Method 969.38 (2000). A handheld Refractometer (Atago, Japan) was used to determine the water content in honey based on the refractive index. The readings were corrected for a standard temperature of $20^{\circ} \mathrm{C}$ by adding the correction factor of $0.00023 /{ }^{\circ} \mathrm{C}$. The moisture content was calculated by using Wedmore's table referring to the refractive index. All measurements were carried out in triplicate and the moisture content is expressed in percentage $(\%)$.

Determination of total soluble solid: The total soluble solid was measured by using a refractometer (Atago Pocket Refractometer) at ambient temperature. The results were expressed in \% Brix.

Determination of electrical conductivity: The electrical conductivity was determined based on the electrical re- sistance by using a conductivity meter (EcoScan COND 6+ Conductivity Meter from Eutech Instrument) [9]. All honey samples were analyzed in triplicate and the results are expressed in $\mathrm{mS} / \mathrm{cm}$.

\subsection{Analysis of Chemical and Scavenging Activity}

Total phenolic content in honey samples was determined by using the Folin-Ciocalteu method described by Singleton et al. [10] with minor modification. A $0.5 \mathrm{~mL}$ of honey solution $(0.1 \mathrm{~g} / \mathrm{mL})$ was mixed with $2.5 \mathrm{~mL}$ of 0.2 $\mathrm{N}$ Folin-Ciocalteu reagent and incubated for five minutes. Then, $2 \mathrm{~mL}$ of sodium carbonate $(75 \mathrm{~g} / \mathrm{L})$ was added and incubated for two hours. After incubation, the absorbance was measured against methanol as blank at $760 \mathrm{~nm}$ using a UV-Vis spectrophotometer (Perkin Elmer, Lamda 25). The calibration curve was constructed using gallic acid $(0-100 \mathrm{mg} / \mathrm{L})$. The measurement was performed in triplicate and the total phenolic content was expressed in $\mathrm{mg}$ of gallic acid equivalents (GAE) per kg of honey.

Total flavonoid content was determined by using the method described by Singleton et al. [10] with minor modification. A $5 \mathrm{~mL}$ of honey solution $(0.1 \mathrm{~g} / \mathrm{mL})$ was mixed with $5 \mathrm{~mL}$ of $2 \%$ aluminium trichloride $\left(\mathrm{AlCl}_{3}\right)$. The complex formation (flavonoid-aluminium) was measured at $415 \mathrm{~nm}$ by using a UV-Vis spectrophotometer (Perkin Elmer, Lambda 25) after ten minutes incubation. The standard curve for total flavonoids content was plotted using rutin $(0-100 \mathrm{mg} / \mathrm{L})$ as a standard chemical. The measurement was performed in triplicate and the total flavonoids content was expressed in mg rutin equivalents (RE) per kg of honey.

The radical scavenging activity of honey was measured according to the 2, 2-diphenyl-1-picryhydrazyl (DPPH) method as described by Velazquez et al. [11] with minor modification. This method measures the reduction of DPPH purple color to yellow color. A $0.75 \mathrm{~mL}$ of honey solution (0.02-0.04 g/mL methanol) was mixed with 1.5 $\mathrm{mL}$ of $0.02 \mathrm{mg} / \mathrm{mL} \mathrm{DPPH}$ solution. The complex mixture against DPPH was measured by using a UV-Vis spectrophotometer (Perkin Elmer, Lambda 25) at $517 \mathrm{~nm}$ after 15 minutes incubation at $25^{\circ} \mathrm{C}$. The sample blank consisted of $0.75 \mathrm{~mL}$ methanol and $1.5 \mathrm{~mL}$ of methanolic DPPH. The ascobic acid standard curve $(0-10 \mathrm{mg} / \mathrm{L})$ was plotted for calibration. The free radical scavenging activity was expressed as $\mathrm{IC}_{50}$.

\subsection{Statistical Analysis}

The data were analyzed by the analysis of variance (ANOVA) using SPSS software (SPSS 16.0). Correlations were carried out by using the Pearson's correlation coefficient $(r)$ in bivariate linear correlations. 


\section{RESULTS AND DISCUSSION}

\subsection{Physical Properties of Honey}

From Table 1, the $\mathrm{pH}$ values of honey samples; Tualang, Gelam and Acacia, were ranging from 3.14 to 3.52, where Tualang honey showed the most acidic value in $\mathrm{pH}$. The $\mathrm{pH}$ values of all honey samples were significantly different $(p=0.000)$ due to the difference in botanical and geographical origin of honey. The parameter of $\mathrm{pH}$ is crucial as it is strongly related to the stability, life expectancy of honey product and fermentation process due to storage $[8,12]$. The $\mathrm{pH}$ values for Malaysian honey reported by Khalil et al. [13]] was slightly higher, which ranged from 3.44 to 3.89 compared to the $\mathrm{pH}$ values reported by Alqarni et al. [14]. However, honey samples from Serbian, Brazil and Uruguayan showed the comparable findings with this study, the $\mathrm{pH}$ were ranging from $3.1-4.14,2.9-3.7$ and $3.00-4.30$, respectively $[8,15,16]$.

Gelam honey was reported to have darker color compared to Acacia and Tualang honey with Pfund scale, 139.00 , 97.00 and $74.00 \mathrm{~mm}$, respectively. All honey samples were statistically different $(p=0.000)$ in color depending on the type of floral fed by bees. Based on the National Honey Board [1], the color of Tualang, Gelam and Acacia honey was categorized as light amber to dark amber. The color of honey might be contributed by pigments such as chlorophylls, carotenoids, flavonoids and derivatives of tannis and polyphenols [17]. The total soluble solid are primarily consisted of sugars; fructose, glucose, and sucrose. Moreover, organic compounds such as acids and minerals also contributed to the total soluble solid in honey. Acacia honey showed the highest soluble solid (74.80\%), followed by Gelam (74.07\%) and Tualang $(72.93 \%)$. The difference of soluble solid might due to the difference in chemical composition of honey.

Acacia honey was reported to have the lowest moisture content compared to Tualang and Gelam honey; $19.53,24.07,25.20 \%$, respectively. Tualang and Gelam honey contained high moisture content, which exceeding $20 \%$, while the moisture content of Acacia honey was within the permitted ranged [18]. The moisture content of honey is a crucial parameter to determine the quality and shelf-life of honey product. The factor of storage combined with the high moisture content in honey could increase the fermentation rate, and leading to the formation of acidified honey because of acetic acid formation. Somehow, the moisture content of honey is highly depending on the climatic change, maturity of honey and harvesting season [19]. Based on Kayacier and Karaman [20], the moisture content might indicate the origin of honey. The tropical country of Malaysia with rainy season all over the year leads to high moisture content in honey. Therefore, Malaysian honey is always treated by evaporation to reduce the water content, simultaneously increase the quality of honey.

The electrical conductivity was the highest in Acacia honey, followed by Gelam and Tualang honey. All honey samples were significantly different in electrical conductiveity $(p=0.045)$. The electrical conductivity measures the ability of honey solution to conduct an electric current. This electric current was carried by ions and the chemical changes in the solution. The factors that contributed to the high value of electrical conductivity might be storage, time, temperature, water content and concentration of ions and minerals $[14,21,22]$. The electrical conductivity affects the $\mathrm{pH}$ of honey, which indicated in the acidity value, depending on the dissolved chemical compound and biochemical process [23].

\subsection{Total Phenols, flavonoids and Antioxidant Properties}

The amount of total phenolic contents was predicted by using the Folin-Ciocalteu reagent from methanolic honey solution. The total phenolic contents in Malaysian honey were expressed in milligram gallic acid equivalent to kilogram of honey. The result obtained (Table 1) showed that the total phenolic contents for honey samples were ranged from 383.79 to $606.17 \mathrm{mg} \mathrm{GAE} / \mathrm{kg}$. Floral honey, Gelam was reported having the highest phenolic contents, followed by Acacia (honeydew honey) and Tualang (floral honey) with $606.17,550.00$ and $383.79 \mathrm{mg} \mathrm{GAE} / \mathrm{kg}$,

Table 1.

\begin{tabular}{|c|c|c|c|}
\hline \multirow{2}{*}{ Parameters (Unit) } & \multicolumn{3}{|c|}{ Honey $($ Mean \pm SD) } \\
\hline & Tualang & Gelam & Acacia \\
\hline $\mathrm{pH}$ & $3.14 \pm 0.06^{\mathrm{c}}$ & $3.52 \pm 0.07^{\mathrm{a}}$ & $3.33 \pm 0.08^{b}$ \\
\hline Moisture (\%) & $25.20 \pm 0.17^{\mathrm{a}}$ & $24.07 \pm 0.12^{b}$ & $19.53 \pm 0.12^{\mathrm{c}}$ \\
\hline Electrical Conductivity, (mS/cm) & $0.91 \pm 0.0012^{\mathrm{c}}$ & $1.02 \pm 0.0089^{\mathrm{b}}$ & $1.09 \pm 0.0030^{\mathrm{a}}$ \\
\hline Total soluble solid, $(\%)$ & $72.93 \pm 0.06^{\mathrm{c}}$ & $74.07 \pm 0.15^{b}$ & $74.80 \pm 0.10^{\mathrm{a}}$ \\
\hline Total phenolics content, $\left(\mathrm{mg}_{\text {gallic acid }} / \mathrm{kg}\right)$ & $383.79 \pm 13.57^{\mathrm{a}}$ & $606.17 \pm 20.36^{\mathrm{a}}$ & $550.00 \pm 21.93^{\mathrm{a}}$ \\
\hline Total flavonoids content, $\left(\mathrm{mg}_{\text {rutin }} / \mathrm{kg}\right.$ ) & $49.04 \pm 0.53^{c}$ & $183.43 \pm 1.70^{\mathrm{a}, \mathrm{b}}$ & $115.96 \pm 4.69^{\mathrm{a}, \mathrm{b}}$ \\
\hline DPPH Radical Scavenging Activity $\left(\mathrm{IC}_{50}, \mathrm{~g} / \mathrm{L}\right)$ & $72.75 \pm 4.52^{\mathrm{a}}$ & $77.41 \pm 62.29^{\mathrm{a}}$ & $90.83 \pm 12.31^{\mathrm{a}}$ \\
\hline
\end{tabular}

\footnotetext{
${ }^{\mathrm{a}, \mathrm{b}, \mathrm{c}}$ Superscript in the same row was compared based on LSD's test $(p<0.05)$. Same superscript means no significant difference.
} 
respectively. However, there is no significant difference $(p=0.471)$ between floral and honeydew honey for total phenolic contents. The similar finding was reported by Beretta et al. [24] and Bertoncelj et al. [6] using floral and honeydew honey for their studies.

The total flavonoid contents of all honey samples were expressed in mg rutin equivalent $/ \mathrm{kg}$ by using rutin standard curve $\left(r^{2}=0.995\right)$. Once again, Gelam honey was reported to have the highest flavonoid contents (183.43 $\mathrm{mg} \mathrm{RE} / \mathrm{kg}$ ), followed by Acacia (115.96 mg RE/kg) and Tualang (49.04 mg RE/kg). There is no significant difference between Gelam and Acacia honey $(p=0.650)$ for total flavonoid content. The amount of flavonoid contents was lower than the phenolic contents in all honey samples. The values of phenolic and flavonoid contents in honey samples were in close agreement with the results reported by Meda et al. [25] and Yao et al. [26]

The free radical scavenging activity was determined based on the DPPH method using the stable radical 2,2diphenyl-1-picryhydrazyl. The radicals are scavenged by delocalization of the spare electron over the molecule. This delocalization would give the purple color in methanol solution and turned to pale yellow after reacting with the substance by donating hydrogen atom. The free radical scavenging activity typically expressed as $\mathrm{IC}_{50}$, to represent the quantity of antioxidant required to reduce the initial concentration of DPPH by $50 \%$. By using $\mathrm{IC}_{50}$, the antioxidant activity increase with the de- creasing of $\mathrm{IC}_{50}$ value [27]. From the Table 1, the $\mathrm{IC}_{50}$ values were ranged from 72.75 to $90.83 \mathrm{~g} / \mathrm{L}$, where Acacia honey reported to have the highest value $(90.83 \mathrm{~g} / \mathrm{L})$, followed by Gelam $(77.41 \mathrm{~g} / \mathrm{L})$ and Tualang $(72.75 \mathrm{~g} / \mathrm{L})$. Acacia honey was the least reactive honey to trap the free radical, compared to Gelam and Tualang honey. However, there is no statistically different between all honey samples ( $p$ $=0.827$ ) for the radical scavenging activity. Somehow, it is important to note that, the presence of peptide, organic acids, enzymes and the product of Maillard reaction would contribute to the antioxidant activity in honey [6].

\subsection{Correlation between Physical, Chemical and Antioxidant Properties}

The physical properties in honey closely related to the presence of antioxidant properties. Indeed, the physical properties of honey depend on the geographical and botanical origin of the nectar. This present study reported that the antioxidant properties have strong correlation with $\mathrm{pH}$, color, electrical conductivity and total soluble solid. Nevertheless, the moisture and free radical scavenging activity of honey samples showed a negative correlation.

From Table 2, the total phenolic contents showed the strong correlation between $\mathrm{pH}$, color and total soluble solid with correlation coefficient, $r=0.979,0.902$ and 0.957 , correspondingly. Besides, the total flavonoid content also exhibited similar correlation with the $\mathrm{pH}(r=$ $0.997)$, color $(r=0.986)$ and total soluble solid $(r=$ 0.839 ). The presence of phenolic acids and flavonoids in honey samples might act as a proton donator leading to the for- mation of acidified honey with low $\mathrm{pH}$ value. The pigments of polyphenolics and flavonoids that exist in honey might contribute to the variable color of honey [17]. The dark honey contributed by the higher content of phenolic compounds [28]. These organic compounds and acids also explained to the strong correlation with the total soluble solid. The free radical scavenging activity exhibited strong correlation with electrical conductivity and total soluble solid with correlation coefficient, $r=0.917$ and 0.921 , respectively. This electric current was carried by ions and controlled by dissolved chemical compound and biochemical process [23]. Strong negative correlation was reported between free radical scavenging activeity and moisture content $(r=-0.998)$. The high moisture content could lead to the fermentation process that could decrease the antioxidant capacity.

Table 2.

\begin{tabular}{|c|c|c|c|c|c|c|c|c|}
\hline & $\mathrm{pH}$ & Color & Moisture & $\mathrm{EC}$ & TSS & TPC & TFC & DPPH-IC ${ }_{50}$ \\
\hline $\mathrm{pH}$ & 1 & & & & & & & \\
\hline Color & 0.971 & 1 & & & & & & \\
\hline Moisture & -0.188 & -0.016 & 1 & & & & & \\
\hline $\mathrm{EC}$ & 0.710 & 0.474 & -0.881 & 1 & & & & \\
\hline TSS & 0.878 & 0.738 & -0.675 & 0.944 & 1 & & & \\
\hline TPC & 0.979 & 0.902 & -0.432 & 0.807 & 0.957 & 1 & & \\
\hline TFC & 0.997 & 0.986 & -0.165 & 0.612 & 0.839 & 0.961 & 1 & \\
\hline DPPH-IC ${ }_{50}$ & 0.246 & 0.083 & -0.998 & 0.917 & 0.921 & 0.624 & 0.246 & 1 \\
\hline
\end{tabular}

Correlations were carried out by using Pearson's correlation coefficient $(r)$; EC: Electrical conductivity, TSS: Total soluble solid, TPC: Total phenolic content, TFC: Total flavonoid content. 


\section{CONCLUSIONS}

The physical properties of honey are closely related with the chemical composition of honey. The composition is dependent on the botanical and geographical origins, in addition to the shelf life of honey. Gelam was reported to have high phenolic and flavonoid contents. The high scavenging activity was also reported in Tualang honey. The physical properties could be used to predict the antioxidant activity in honey based on the strong correlation for $\mathrm{pH}$, color, electrical conductivity and total soluble solid. The establishment of the correlation could be the easiest way to determine the quality of honey.

\section{ACKNOWLEDGEMENTS}

The authors would like to thank Ms. Nur Ardawati Adnan and Ms. Norfahana Abd-talib for their support and guidance. This research work was granted by GUP (Tier 1) Fund under the Research Alliance of Biotechnology (7125.00H05), UTM.

\section{REFERENCES}

[1] The National Honey Board. (2003) Honey-Health and Therapeutic Qualities. The National Honey Board, USA.

[2] Gheldof, N. and Engeseth, N.J. (2002) Antioxidant capacity of honeys from various floral sources based on the determination of oxygen radical absorbance capacity and inhibition of in vitro lipoprotein oxidation in human serum samples. Journal of agricultural and food chemistry. 50, 3050-3055. doi:10.1021/jf0114637

[3] Turkmen, F.N., Sari, E., Poyrazoglu, S. and Velioglu, Y.S. (2006) Effects of prolonged heating on antioxidant activity and colour of honey. Food Chemistry. 95, 653-657. doi:10.1016/j.foodchem.2005.02.004

[4] Gheldof, N., Wang, X.-H. and Engeseth, N .J.(2002)Iden tification and quantification of antioxidant components of honeys from various floral sources. Journal of agricultural and food chemistry, 50, 5870-5877. http://dx.doi.org/10.1021/jf0256135PMid:12358452

[5] Gomez-Carvaca, A.M., Gomez-Romero, M., Araez-Roman, D., Segura-Carretero, A. and Fernandez-Gutierrez, A.(2006) Advances in the analysis of phenolic compounds in products derived from bees. Journal of Pharmaceutical and Biomedical Analysis, 41, 1220-1234. doi:10.1016/j.jpba.2006.03.002

[6] Bertoncelj, J., Dobersek, U., Jamnik, M. and Golob, T. (2007) Evaluation of the phenolic content, antioxidant activity and colour of Slovenian honey. Food Chemistry, 105, 822-828. doi:10.1016/j.foodchem.2007.01.060

[7] Katalinic, V., Milos, M., Kulisic, T. and Jukic, M. (2006) Screening of 70 medicinal plant extracts for antioxidant capacity and total phenols. Food Chemistry, 94, 550- 557. doi:10.1016/j.foodchem.2004.12.004

[8] Silva, T.M.S., dos Santos, F.P., Evangelista-Rodrigues, A., da Silva, E.M.S., da Silva, G.S., de Novais, J.S., dos Santos, F.D.A.R. and Camara, C.A.(2013) Phenolic com- pounds, melissopalynological, physicochemical analysis and antioxidant activity of jandaíra (Melipona subnitida) honey. Journal of Food Composition and Analysis, 29,10-18. doi:10.1016/j.jfca.2012.08.010

[9] Saxena, S., Gautam, S. and Sharma, A.(2010) Physical, biochemical and antioxidant properties of some Indian honeys. Food Chemistry, 118, 391-397. doi:10.1016/j.foodchem.2009.05.001

[10] Singleton, V.L., Orthofer, R. and Lamuela-Raventos, R.M. (1999) Analysis of total phenols and other oxidation substrates and antioxidant by means of Folin-Ciocalteu reagent. Methods in Enzymology, 299, 152-178. doi:10.1016/S0076-6879(99)99017-1

[11] Velázquez, E., a Tournier, H., Mordujovich de Buschiazzo, P., Saavedra, G. and Schinella, G.R.(2003) Antioxidant activity of Paraguayan plant extracts. Fitoterapia. 74, 91-97. doi:10.1016/S0367-326X(02)00293-9

[12] Gomes, T., Feás, X., Iglesias, A. and Estevinho, L.M. (2011) Study of organic honey from the Northeast Portugal. Molecules, 16, 5374-5386. doi:10.3390/molecules16075374

[13] Khalil, M.I., Sulaiman, S. and Gan, S.H. (2010) High 5-hydroxymethylfurfural concentrations are found in Malaysian honey samples stored for more than one year. Food and chemical toxicology, 48, 2388-2392. doi:10.1016/j.fct.2010.05.076

[14] Alqarni, A. S., Owayss, A. and Mahmoud, A. (2012) Physicochemical characteristics, total phenols and pigments of national and international honeys in Saudi Arabia. Arabian Journal of Chemistry. In press. doi:10.1016/j.arabjc.2012.11.013

[15] Lazarevic, K.B., Andric, F., Trifkovic, J., Tesic, Z. and Milojkovic-Opsenica, D. (2012) Characterisation of Serbian unifloral honeys according to their physicochemical parameters. Food Chemistry, 132, 2060-2064. doi:10.1016/j.foodchem.2011.12.048

[16] Corbella, E. and Cozzolino, D. (2006) Classification of the floral origin of Uruguayan honeys by chemical and physical characteristic combined with chemometrics. LWT-Food Science and Technology, 39, 534-539. doi:10.1016/j.lwt.2005.03.011

[17] Juszczak, L., Socha, R., Roznowski, J., Fortuna, T. and Nalepka, K. (2009) Physicochemical properties and quality parameters of herbhoneys. Food Chemistry, 113, 538-542. doi:10.1016/j.foodchem.2008.07.098

[18] European Union, (2001) Council Directive 2001. EC relating to honey. Official Journal of the European Communities, L10, 47-52.

[19] Finola, M. S., Lasagno, M. C. and Marioli, J. M. (2007) Microbiological and chemical characterization of honeys from central Argentina. Food Chemistry, 100, 1649-1653. doi:10.1016/j.foodchem.2005.12.046

[20] Kayacier, A., and Karaman, S. (2008) Rheology and some physicochemical characteristic of selected Turkish honeys. Journal of Texture Studies, 39, 17-27. doi:10.1111/j.1745-4603.2007.00127.x

[21] Kaptan, B., Kayişoğlu, S. and Demirci, M. (2011) The relationship between some physico-chemical, microbi- 
ological characteristic and electrical conductivity of milk stored at different temperature. Journal of Tekirdag Agricultural Faculty, 8, 13-22.

[22] Guo, W., Liu, Y., Zhu, X. and Zhuang, H. (2011) Sensing the water content of honey from temperature-dependent electrical conductivity. Measurement Science and Technology, 22(085706), 1-5. doi:10.1088/0957-0233/22/8/085706

[23] Deas, M.L. and Orlob, G.T. (1999) Klamath river modeling project. Report No: 99-04.

[24] Beretta, G., Granata, P., Ferrero, M., Orioli, M. and Facino, R. M. (2005). Standardization of antioxidant properties of honey by a combination of spectrophotometric/fluorimetric assays and chemometrics. Analytica Chimica Acta, 533, 185-191. doi:10.1016/j.aca.2004.11.010

[25] Meda, A., Lamien, C.E., Millogo, J., Romito, M. and Nacoulma, O.G. (2005) Physicochemical analyses of bur- kina fasan honey. Acta Veterinaria Brno, 74, 147-152. doi:10.2754/avb200574010147

[26] Yao, L., Datta, N., Tomas-Barberan, F.A., Ferreres Federico,Martos, I. and Singanusong, R.(2003) Flavonoids, phenolic acids and abscisic acid in Australian and New Zealand Leptospermum honeys. Food Chemistry, 81, 159-168. doi:10.1016/S0308-8146(02)00388-6

[27] Molyneux, P. (2004) The use of the stable free radical diphenylpicrylhydrazyl (DPPH) for estimating antioxidant activity. Songlanakarin Journal of Science and Technology, 26, 211-219.

[28] Ferreira, I.C.F.R., Aires, E., Barreira, J.C.M. and Estevinho, L.M. (2009). Antioxidant activity of Portugese honey sample: Different contributuins of entire honey and phenolic extract. Food Chemistry, 114, 1438-1443. doi:10.1016/j.foodchem.2008.11.028 